\title{
Troublesome relationships
}

\section{David Dean}

The Human Career: Human Biological and Cultural Origins. By Richard G. Klein. University of Chicago Press: 1989. Pp. 524. £31.95, \$45.95.

The Hominid Gang: Behind the Scenes in the Search for Human Origins. By Delta Willis. Viking: 1989. Pp. 352. \$19.95.

DURING the past decade, most teachers of undergraduate courses in palaeoanthropology have used Wolpoff's comprehensive, but now dated, text Paleoanthropology (Knopf, 1980). The Human Career is likely to take over as the 'mainstream' textbook of the early 1990s.

Klein, a Plio-Pleistocene archaeologist, is in a unique position to write on human evolution. He is not in the middle of the taxonomic battles that have dominated other textbooks, often at the expense of reporting important archaeology debates. Klein's inclusion of archaeological and geological evidence gives palaeoanthropology its fullest range and depth.

The section on primate ancestors covers the debates on the primate petrosal bulla, the catarrhine status of Amphipithecus and Pondaungia, the relationship of the Fayum taxa to later catarrhines, platyrrhine origins and the diversity of Miocene apes. But a teacher using this book would need a fuller discussion of Oligocene and Miocene catarrhines. Again, despite a thorough discussion of the main dating methods, the issue of molecular clocks is mentioned all too briefly.

In his discussion of the statigraphy and dating of the African australopithecine and early Homo sites, Klein presents the morphology of important specimens in accurate illustrations adapted from well-known publications. He provides a framework and discusses the main controversies: gracile versus robust, bipedalism, how many species, hunting versus scavenging, and so on. Not unexpectedly, Klein concludes that Oldowan peoples were "probably far less bloodthirsty than popular authors such as Ardrcy (1961, 1976) have imagined".

Klein presents the history of the discoveries of Homo erectus by Dubois, Black, Weidenreich, von Koenigswald and later workers in masterly fashion. Issues such as the current disagreement over whether the Far Eastern specimens represent an evolutionary dead-end or show regional continuity with populations living in those areas today are also covered. In the case of the dead-end hypothesis, few would argue with Klein that "the validity of this hypothesis [is] far more important than finding a precise taxonomic assignment for key European, African, and Asian fossils". Klein's presentation is only slightly behind in covering the current debate on the reality of the Movius line and the dating of the earliest Far Eastern sites, but these issues are often ignored in other textbooks.

Klein makes a strong case for the origin of earliest $H$. sapiens as a glacial Middle Pleistocene population that became adapted to either a cold Europe or a dry Africa, together with the mainstream view that no European $H$. erectus is yet documented. Klein subscribes to the traditional view that all the European fossils older than 130,000 years are archaic $H$.

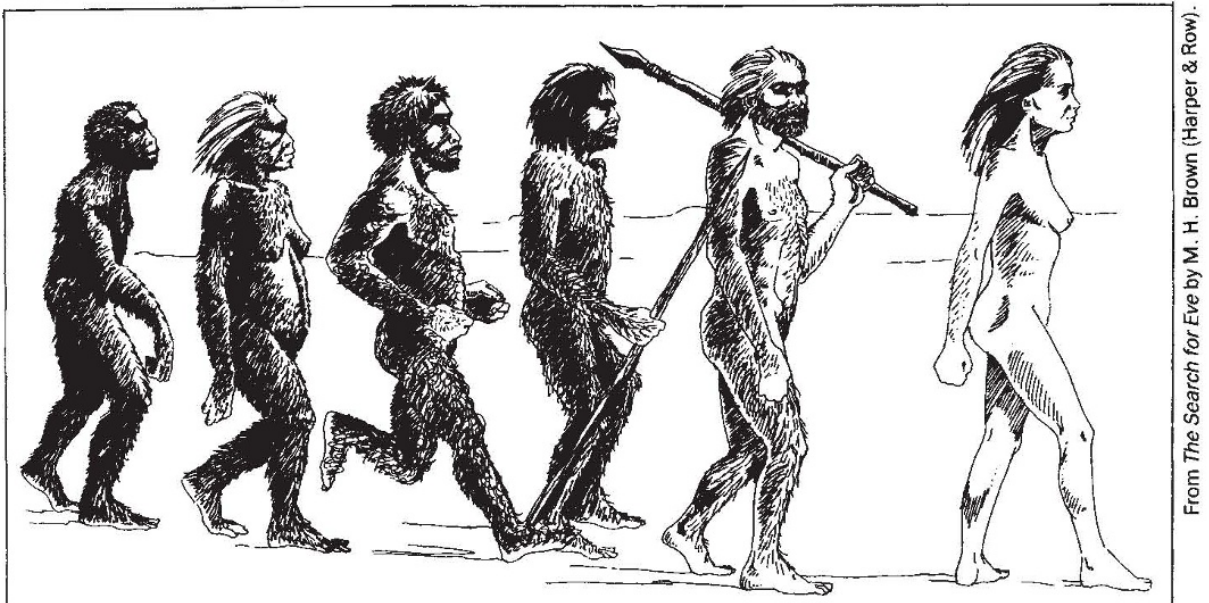

A standard illustration seen on museum walls and in school textbooks, these reconstructions suggest a far more concrete knowledge of human evolution than we actually possess.

sapiens; but he adds that it "seems reasonable to hypothesize an evolutionary sequence from the earlier group [ca. 500,000200,000 years] to the later one [ca. 200,000 130,000 years] to the Neanderthals".

Neanderthals are presented as "the last truly 'primitive' human group". Late archaic specimens and stone-tool industries from outside Europe are also detailed. Klein then presents exhaustive evidence that modern human populations appeared some time between 250,000 and 50,000 years ago, probably first in Africa more than 90,000 years ago. Klein is equivocal on the fate of the Neanderthals: "Increasingly, the answer seems to be that they were physically usurped, but the issue remains debatable."

In making the case for Cro-Magnon superiority over both Neanderthals and their early anatomically modern brethren, Klein seems to equate European Aurignacian tools with modern behaviour: ". . in both the Near East and Africa, anatomical modernity antedates behavioural modernity . . . Neurologically, they may have lacked the fully modern capacity for culture."

Willis's Hominid Gang is the group of Kenya Museum staff that searches for fossils. The subtitle of the book promises gossip, mood lighting and piquant vignettes, all of which are delivered. Willis reports on the palaeoanthropological meetings she attended over the past 12 years, as well as on several trips to Africa. With a reporter's knack, she recounts conversations, debates and personal rivalries among the 'heavyweights'.

Unfortunately, her presentation of the facts is such that I would not recommend this book to the lay public at which it is aimed. Willis misuses taxonomic terms and common names alike. She says the sample of Kenyan Australopithecus includes "robust and hyper-robust (or boisei)". But $A$. robustus is only known from South Africa. Constant reference to afarensis (not $A$. afarensis) implies to lay readers that species are correctly referred to by their trivial names alone.

Willis also confuses simple facts. More than once she says hominoids have a Vshaped jaw. This is correct for lower primates, but ape mandibles are most often described as U-shaped and hominid mandibles as "parabolic". She claims: "Erectus skulls found in Asia have a sagittal crest, but this is absent from some erectus skulls found in Europe and Africa.

Erectus skulls have a bony bump at the base of the skull called an occipital bun (as in a lady's hair bun)." But there is no widely acknowledged $H$. erectus in Europe, nor do any $H$. erectus specimens exhibit a sagittal crest (as do robust australopithecines or gorillas) or an occiptial bun (as do Neanderthals sensu stricto). There is also a strange reference to 'three lemurs': "This is an eye-eye; those are two mouse types" (p. 291). This might lead readers to assume that the aye-aye is the only stereoscopic primate.

Taken as introductory-level texts, The Human Career is successful whereas The Hominid Gang isn't. Palaeoanthropology is not a soft, descriptive science as some would believe. Organization and factchecking are as important to its reportage as is testing of hypotheses to its praxis.

David Dean is in the Department of Anthropology, City University of New York, New York, New York 10036-8099, USA.

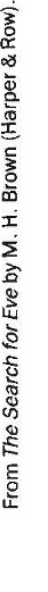

